\title{
Enhancing physicians' communication skills is not enough: an approach by Habermas social theories
}

\author{
Wacharin Sindhvananda
}

\begin{abstract}
Introduction: A high gap of communication between physicians and patients has been widely documented. Based on Habermas, communication problems originally came from systematization and technology, in which these conditions lead physicians to form inappropriate communications called 'strategic action' (SA). To avoid communication conflicts, Habermas promotes the 'communicative action' (CA) The objective of this study was to prove theoretical conditions of occurrences of SA and CA in physicians' thoughts.
\end{abstract}

Methods: Samples were collected from in-training physicians at King Chulalongkorn Memorial Hospital. A self-administered, Thai-version, questionnaire was the study tool. The questionnaire was composed of eight scales that were constructed and qualified. A theoretical model of multiple relationships causing SA and CA was tested by path analysis.

Results: The total respondents were 173. Analyzed data indicated the theoretical model was valid $(R M S E A=0.000)$. Conditions that significantly influenced SA were 'medical ideology (MI)' (total effect $=0.10$ ), 'system ideology $(\mathrm{SI})$ ' (total effect $=0.09$ ) and 'cognitive-instrumental rationality' (total effect $=$ 0.30). Conditions that significantly influenced CA could not be identified. Based on the theory, 'morality ideology should influence moral-practical rationality', but 'system ideology' was found to significantly influence instead (path coefficient $=0.25$ ).

Discussion: The 'technocratic ideology' (MI and $\mathrm{SI}$ ) together with the cognitive-instrumental rationality was proved to lead physicians' SA. These findings confirmed 1) the significance of thoughts that base personal actions and 2) an extension of systematization that influenced on moral rationality. Probably, this influence might obstruct the natural moral developments so that CA could not be developed. In other words, systematization facilitates SA.

Conclusion: Physicians communications were fundamentally SA because of continuing embedded 'technocratic ideology'. Therefore, solving physicians' inappropriate communication should realize the significance of ideology and rationality levels, such as, cessation of embedding 'technocratic ideology'.

Keywords: communicative action, strategic action, technocratic ideology, moral development

\section{Introduction}

For many decades, complexities of systemization and medical technology have influenced the medical world. One of its consequences, a higher gap of communication between physicians and patients has been

Corresponding author:

Wacharin Sindhvananda, M.D., M.P.H.

Department of Anesthesiology

Faculty of Medicine, Chulalongkorn University,

Rama IV Road, Patumwan, Bangkok 10330, Thailand.

Email: wacharins@hotmail.com increased and widely emerged (Myers, 2004; Lescale et al., 1996). Almost of these gaps of communication or communication conflicts have come from inappropriate communication of physicians (Levinson et al., 1999). Therefore, an enhancement of physician communication skills has been interested and proposed in medical educations. As such, physicians are taught to provide a two-way communication, more listening, and more consideration (Hawken, 2005; Levinson et al., 1999). However, results of these attempts are still questionably (Back \& Arnold, 2005). In Habermas' theories, a common communication pattern called 'strategic action' (SA) are described that it is 
generally used by individuals for communication (Habermas, 1984). As SA is a communication toward only a speaker's success, therefore it brings about lacks of mutual understanding. Interestingly, Habermas claims that a communication pattern of an individual is influenced by some personal complexity of thought. Therefore, physicians' inappropriate communication patterns might not be effectively corrected just by promoting the superficial level of how appropriate communication should be. Based on the theories, another communication pattern called 'communicative action' (CA) is a possible way to solve communication conflicts. As a result, this study was primarily aimed to investigate the validity of the theoretical-based causal paths of occurrences of SA and CA in physicians' thoughts. For the hope that physicians' inappropriate communications might be effectively solved.

\section{Method}

This study was a quantitative-approached descriptive study. The methodology was approved by the ethics committee of the International Review Board of Mahidol University as it was a part of a dissertation. Samples were general physicians who were studying in the first year of postgraduate programs at King Chulalongkorn Memorial Hospital (academic year 2009).

Figure 1: Theoretical multiple causal relationships in occurrences of 'communicative action' and 'strategic action' (The Theoretical Model)

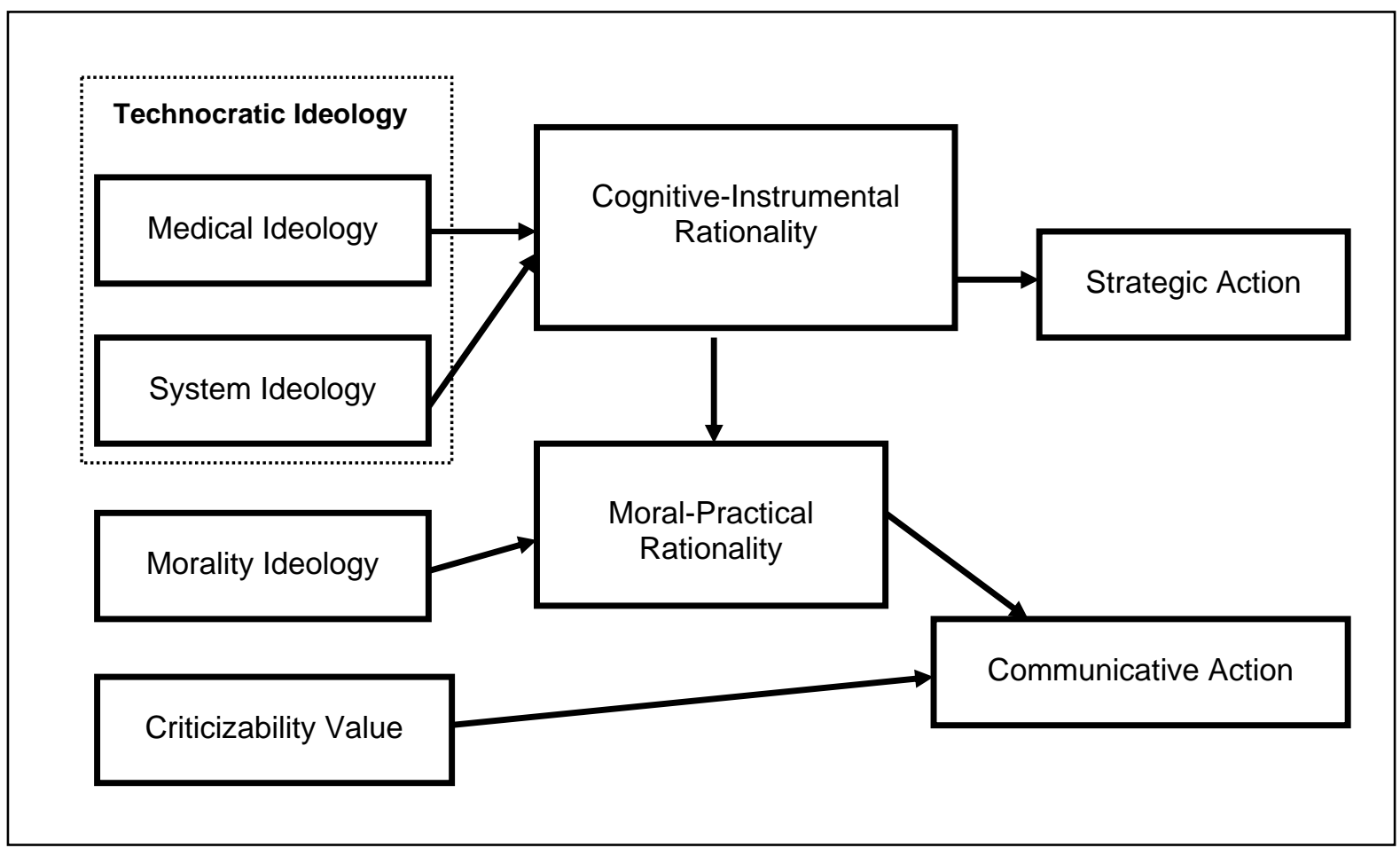


Table 1: Operation definitions of Theoretical-Based Constructs

\begin{tabular}{|c|c|}
\hline Terms & Definition \\
\hline ideology & $\begin{array}{l}\text { a set of ideas or body of thoughts as a comprehensive vision, a } \\
\text { way of looking at things, as in common sense }\end{array}$ \\
\hline technocratic ideology & $\begin{array}{l}\text { body of thoughts regarding application of science, technology } \\
\text { and systemization for controlling nature and social beings }\end{array}$ \\
\hline medical ideology & $\begin{array}{l}\text { a set of scientific ideas regarding controls and reduction in } \\
\text { medical perspectives }\end{array}$ \\
\hline system ideology & $\begin{array}{l}\text { a set of systemizing ideas regarding formal arrangement, } \\
\text { productivity, and efficiency }\end{array}$ \\
\hline morality ideology & $\begin{array}{l}\text { beliefs, thoughts, norms, values, and motivations according to } \\
\text { social integration and humanity }\end{array}$ \\
\hline criticizability value & $\begin{array}{l}\text { two sets of ideas that provide openness to being criticized by } \\
\text { others (participation idea) and ability to criticize others (critical } \\
\text { idea) }\end{array}$ \\
\hline cognitive-instrumental rationality & $\begin{array}{l}\text { reasons or decisions based only on empirical truth and } \\
\text { standard for the results of self-success and effectiveness } \\
\text { without considering multiple dimensions. (Kohlberg moral } \\
\text { stages 1and 2) }\end{array}$ \\
\hline moral-practical rationality & $\begin{array}{l}\text { reasons or decisions based on non-materialistic values such as } \\
\text { morals and norms considering particular contexts (Kohlberg } \\
\text { moral stage } 3,4,5 \text {, and } 6 \text { ) }\end{array}$ \\
\hline strategic action & $\begin{array}{l}\text { speech acts that imply lack of four validity claims or aim to self- } \\
\text { success }\end{array}$ \\
\hline communicative action & $\begin{array}{l}\text { speech acts that completely contain four validity claims or aim } \\
\text { to mutual understanding }\end{array}$ \\
\hline validity claims & $\begin{array}{l}\text { four aspects (comprehensibility, truth, appropriateness, and } \\
\text { sincerity) of concern implying in speech acts }\end{array}$ \\
\hline comprehensibility claims & linguistically understandable utterance \\
\hline truth claim & $\begin{array}{l}\text { utterances that are true based on relevant evidences, or can be } \\
\text { proved to be true as claimed }\end{array}$ \\
\hline appropriateness claim & $\begin{array}{l}\text { utterances that show examinations regarding suitability in a } \\
\text { particular context }\end{array}$ \\
\hline sincerity claim & $\begin{array}{l}\text { speech acts that provide/induce sharing behind presupposition, } \\
\text { such as knowledge, intention, and values, etc. }\end{array}$ \\
\hline
\end{tabular}


Table 2: Direct and indirect effects from other constructs toward 'Strategic Action'

\begin{tabular}{lrrrrrrr}
\hline & $\begin{array}{r}\text { Medical } \\
\text { Ideology }\end{array}$ & $\begin{array}{c}\text { System } \\
\text { Ideology }\end{array}$ & $\begin{array}{c}\text { Morality } \\
\text { Ideology }\end{array}$ & $\begin{array}{r}\text { Criticiz } \\
\text { ability } \\
\text { Values }\end{array}$ & $\begin{array}{r}\text { Cognitive- } \\
\text { Instrumental } \\
\text { Rationality }\end{array}$ & $\begin{array}{r}\text { Moral- } \\
\text { Practical } \\
\text { Rationality }\end{array}$ & $\begin{array}{c}\text { Commu- } \\
\text { nicative } \\
\text { Action }\end{array}$ \\
\hline Direct effect & - & - & - & -0.04 & $0.19^{\star}$ & 0.16 & 0.18 \\
Indirect effect & $0.10^{*}$ & $0.09^{*}$ & -0.01 & 0.06 & $0.14^{\star}$ & 0.02 & 0.02 \\
Total effect & $0.10^{*}$ & $0.09^{*}$ & -0.01 & 0.02 & $0.33^{\star}$ & 0.18 & 0.20 \\
\hline
\end{tabular}

Remark: Values are in term of standardized solution, * $=p$-value $<0.05$

The study tool was a self-administered questionnaire including eight psychometric scales. The scales were constructed based on Habermas theories in Thai. Eight theoretical constructs involved with the research question included 'medical ideology' (MI), 'system ideology' (SI), 'morality ideology' (MRI), 'criticizability value' (CV), 'cognitiveinstrumental rationality' (CIR), 'moral-practical rationality' (MPR), SA and CA.

A structural model of relationships among eight constructs was formed based on the theories (Habermas, 1984). Basically, the theories stated a person has adopted social influences in aspects of 'ideology' and/or 'values'. Both of them are grounds for decision making or reasoning. Later on, personal specific actions are manifested based on the decisions. In particular, Habermas mentioned an influence of 'technocratic ideology' on a personal specific reasoning called CIR and a specific action called SA. On the contrary, CA is still indistinct but should be associated with another specific reasoning called MPR and a special value called 'criticiazability value'. Habermas focused that 'criticizability value' is neccessary for producing CA (Baxter, 2002). As a result, the theoretical model of SA and CA occurrences was demonstrated (Figure 1).

Operation definitions of the eight variables and their associations were initially clarified in order to guide constructions of the scales (Table 1). A simple scale was designed for the ideologies/value (MI, SI, MRI and CV). These scales were to generate simple phrases or sentences regarding their meanings and to assess the degree of agreement from 1 to 6 Likert-type scale. For the rationalities (CIR, MPR) and the communication patterns (SA, $C A)$, vignette-based scales were designed. All the vignettes were created according to endof-life care contexts. Assessments of the rationalities were on reasons that were generated based on definitions of CIR or MPR, and agreement of the constructed reasons was to evaluate from 1 to 7 Likert-type scale. Assessment of the communication patterns were on speech acts that constructed based on definitions of SA or CA. A possibility to speak of each speech act was to evaluate by 1 to 6 Likert-type scale.

Face validity was qualified by two medical doctors, a sociologist, and a psychologist for all the vignettes and the assessed items. All of them passed the verification of face validity before processing the internal-consistency reliability test.In the final-version questionnaire (Sindhvananda, 2010), alpha values of reliability were $0.9087,0.8238,0.8481$, and 0.8136 of $\mathrm{MI}, \mathrm{SI}, \mathrm{MRI}$, and CV respectively. The alpha values of CIR, MPR, SA, and CA were $0.8330,0.7840,0.8829$ and 0.8883 consecutively.

Research assistants approached all of the tentative samples by introducing details of the study; however, the tentative samples could make their own decisions (not) to be engaged in this study.

The item scores of a variable (scale) was accumulated into a 'total' score. The 'total' scores of eight scales were processed simultaneously using path analysis with LISREL student version 8.80. Demographic data, such as age and gender was analyzed by frequency, mean and standard deviation. 


\section{Results}

Complete responses were 173 from a total of 187 in-trained physicians (92.51\%): 110 females (63.58\%) and 63 males (36.42\%). The average age was $27.08 \pm 1.08$ years. Range of the age was 24-33 years.

Two common fit criteria-a low value of chisquare value with no statistical significance and a lower RMSEA than 0.05- revealed that the observed model is congruent with the theoretical model (Chi-square value $=6.75$, p-value $=0.87$, RMSEA = 0.000). However, the observed model was formed with some different relationships from the theoretical model (Figure 2).

According to the observed model, three theoretical-based significant causal relationships were from MI to CIR (path coefficient $=0.30$ ), from CIR to SA (path coefficient $=0.19$ ), and from CIR to MPR (path coefficient $=0.64$ ) were demonstrated. The other two significant causal relationships, did not state the theories, were from SI to MPR (path coefficient $=0.25$ ), and from SA to CA (path coefficient $=0.70$ ).

Direct and Indirect causal effects toward SA had been revealed in Table 2. MI and SI, as indirect effects significantly caused SA. CIR, as the only direct effect significantly caused SA.

According to the averaged mean scores of eight variables with their subcomponents (Table 3), it was striking that a 'sincerity' validity claim of $\mathrm{CA}$ found to be scored the lowest than other validity claims. Ignorance in 'comprehensibility' validity claim of SA to be scored the highest.

\section{Discussion}

The main finding of this study was that the structural model deriving from the observed scores found to be in harmony with the theoretical model. By a quantitative approach, this study was a foremost provability of causal relationships from 'technocratic ideology' to CIR then to SA (Habermas, 1984; Baxter, 2002). These findings confirmed the concept that a personal communication pattern comes from his I her rationalities and some embedded values. More importantly, the findings demonstrated that physicians' thoughts were really influenced by science and systemization. Also, physicians really intended to use SA in communication because of their CIR.
SA, a communication pattern, is simply defined as communications induced by selfinterests (Habermas, 1984). It can cause misunderstanding or discontent among physicians and patients. Notably, SA is daily reproduced by means of no provision on debates or manipulation to cause passive participation. Most of these circumstances are commonly found in medical encounters (Graham \& Oakley, 1982; Mishler, 1984). Corresponding to the results of this study, physicians tended to use SA. For the sake of patients, physicians' SA should be inhibited. This study demonstrated the important causal root of SA, which was CIR. CIR is gradually developed by the positive values on 'being control' (MI), 'being effective' (SI) and 'having standard' (SI).In order to avoid SA, devaluing of these ideologies should be promoted. Despite the fact that these values are necessary in medical profession, but devaluing can make a balance of these perspectives in mind.

Focusing on the against-theory findings, a significant causal path from SI to MPR was found. This result is a warning sign that systemization presently extends to involve moral logics of physicians. That meant development of moral reasoning might not be natural as Kohlberg stated (Kohlberg, 1984). Systemization might disturb moral development to be a higher stage. Because following standard; rules and laws are the moral decisions of the $4^{\text {th }}$ moral stage (Kohlberg, 1984). Notably, personal moral decision should be developed till the $6^{\text {th }}$ moral stage. The study findings that showed a highly significant causal relationship from CIR to MPR might imply interference of systemization on physicians' moral reasoning. For example of actual situations, medical ethics is usually set teaching and learning under systemization. This situation might be the way mimics CIR influencing MPR. As a result, some physicians might prefer making a decision based on medical standard to compassion. In addition, some physicians might be confused whether following medical perspectives or following some ways deviating from medical perspectives, but for the sake of patient. At the present, the situations that patients seek for their autonomy are increasing. Therefore, physician-patient conflicts would be increased in the future if physicians still make decisions predominately based on 'systemization'. 
Regarding the validity claims, 'comprehensibility' to be scored the highest of the other SA validity claims. It meant that physicians predominately ignored to communicate with patient by using understandable words. Based on previous hermeneutic studies, the studies found physicians intentionally used technical terms to lead patients to do what they want (Mishler, 1984; Scambler, 2001). On the contrary, 'sincerity' scored the lowest on CA validity claims. It meant that physicians do not share these behind presuppositions while communicating. It might be from their views of non necessity, such as some clinical events regardless of biomedical theories, and their positive values on using medical format of communication, such as medical interview (Waitzkin, 1989). This kind of communication should be counted in a mild form of SA called 'systemic distorted communication' (Scambler, 2001). As such, it could say that physicians use SA while communicating with patients both with and without intention. These results reconfirmed that 'technocratic ideology' is controlling physicians both via physicians' perspectives and behaviors of communication. A limitation of this study was that evaluation validity claims could be done only on the part of physicians. In real circumstances, validity claims should be evaluated from both the speakers and listeners. Therefore, it possibly could be that some physicians at medical encounters might share some presuppositions because they are induced by skeptical patients. However, the assessments were on the intentional level. Physicians might change the communicative pattern in the real circumstances.

Moreover, this study was designed to evaluate conflicts regarding end-of-life care including euthanasia since these situations gave the highest possibility to have multidimensional debates among physicians and patients/relatives than that of other medical contexts. Furthermore, the target population was aimed to be general practice physicians. Regarding the sample size, it should be ten times the parameters. However, the sample size over 100 is acceptable (Holye, 1995).

Figure 2: Multiple causal relationships analyzed from the observed data (The Observed Model)

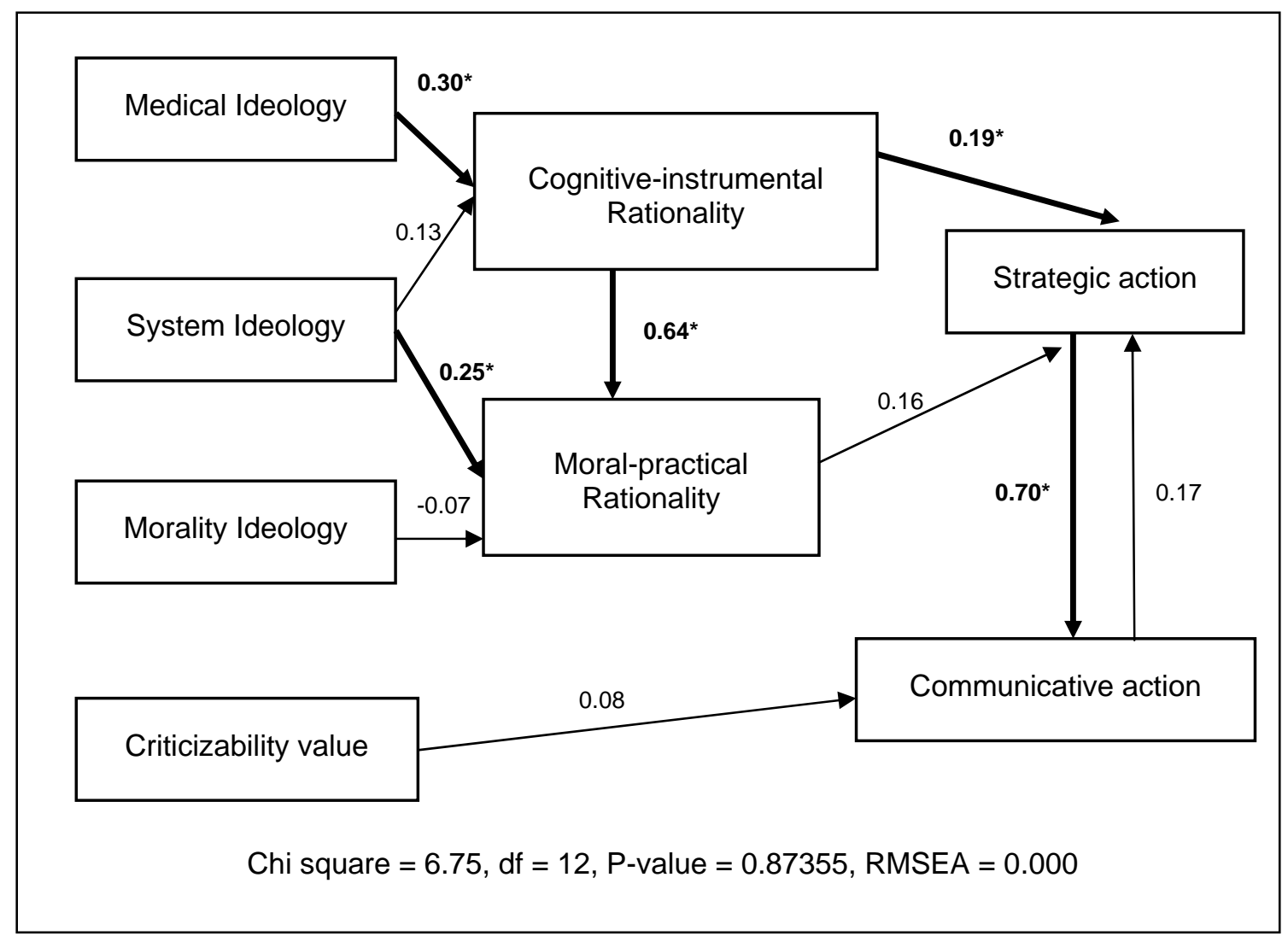


Table 3: The Means and Standard Deviations of total scores and subscale scores of eight Theory-Based Constructs

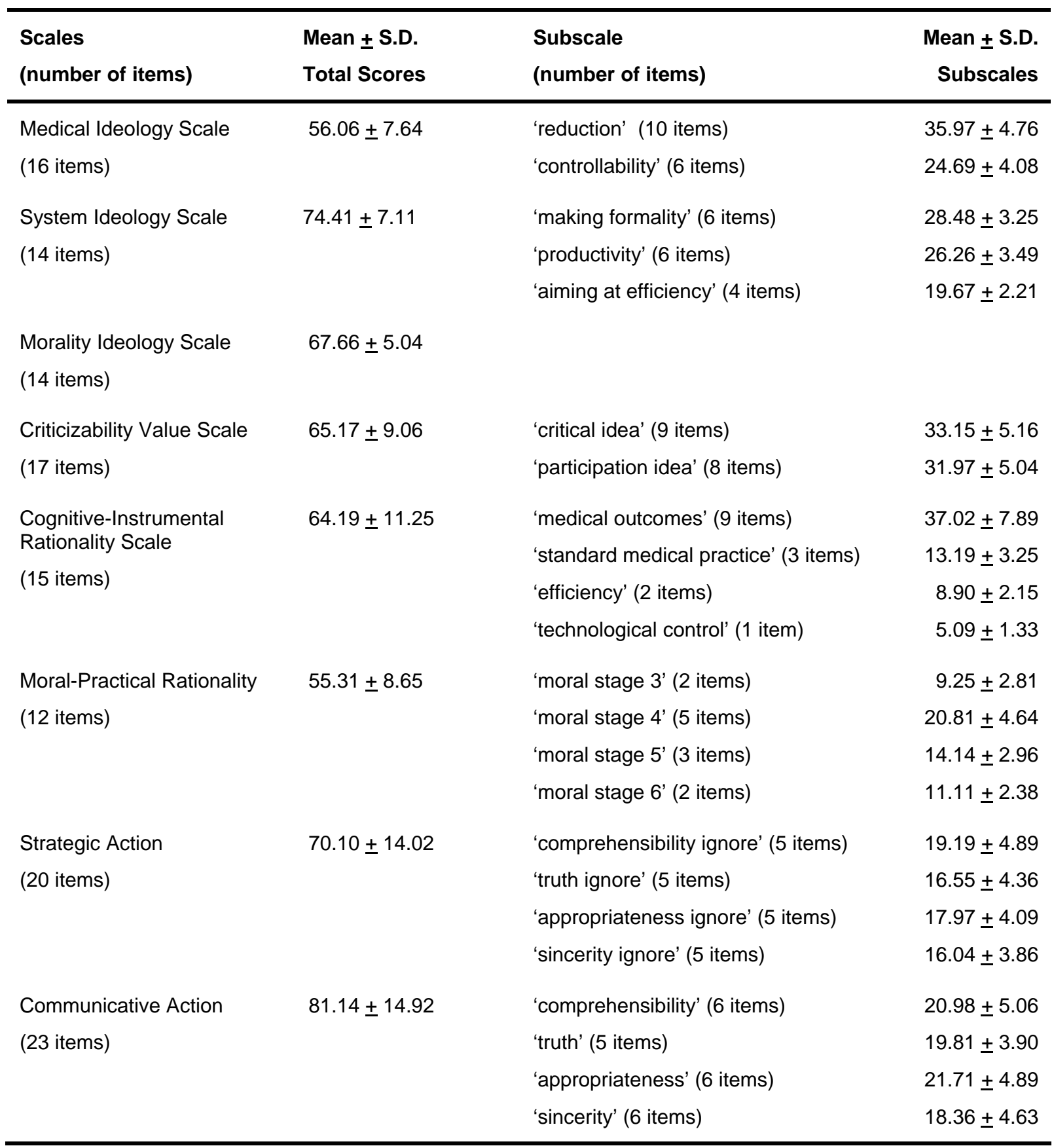




\section{Conclusion}

Approached by social theories, causal relationships from 'technocratic ideology' to CIR then to SA in physician thoughts were valid. Remarkably, a significant causal relationship from SI instead of MRI to MPR was found. This might imply some changes in moral development due to systemization. In addition, physicians' communication patterns fundamentally seemed to be SA. Consequently, solving physicians' inappropriate communication should also concern on the ideological and the rational levels. Devaluing 'technocratic ideology' is an example.

\section{Acknowledgements}

The author is grateful for the questionnaire construction assisted by Assistant Professor Dr.Veena Sirisook and Associate Professor Dr. Mullika Muttiko.

\section{References}

Back, A.L. \& Arnold, R.M. (2005) Dealing with conflict in caring for the seriously ill: "It was just out of the question", JAMA, 293(11), pp.13741381.

Baxter, H. (2002) System and life world in Habermas's theory of law, Cardozo Law Review, 23, pp. 473-600.

Graham, H. \& Oakley, A. (1982) Completing ideologies of reproduction: medical and maternal perspectives on pregnancy, In: Roberts H, (ed.) Women, Health and Reproduction, $1^{\text {st }}$.ed., London: Roudledge \& Kegan Paul, pp. 50-74.

Habermas, J. (1984). Theory of communicative action, Boston: Beacon Press, pp. 1-200.

Hawken, S.J. (2005) Good communication skills: benefits for doctors and patients, New-Zealand Family Physicians, 32(3), pp. 186-189.

Hoyle, R.H. (1995) The structural equation modeling approach: Basic concepts and fundamental issues, In: Hoyle, R. H., (ed.) Structural Equation Modeling: concepts, issues, and applications. $1^{\text {st }}$.ed., Thousand Oaks, CA: SAGE, pp. 1-15.
Kohlberg, L. (1984) Essays on moral development: The psychology of moral development, San Francisco: Harper and Row, pp. 121-150.

Lescale, K.B., Inglis, S.R., Eddleman, K.A., Peeper, E.Q., Chervenak, F.A.. \& McCullough, L.B. (1996) Conflicts between physicians and patients in non-elective cesarean delivery: incidence and the adequacy of informed consent, Am J Perinatol, 13(3), pp. 171-176.

Levinson, W., Gorawara-Bhat, R., Dueck, R., Egener, B., Kao, A., Kerr, C., Lo, B., Stein, T., Perry, D., Pollitz, K., Reifsteck, S.J. \& KempWhite, M. (1999) Resolving disagreements in the patient-physicians relationship: tools for improving communication in managed care, JAMA, 282(15), pp.1477-1483.

Mishler, E.G. (1984) The Discourse of Medicine: Dialectics of medical interview, 1st.ed., Norwood, NJ: Ablex, pp. 35-150.

Myers, D.A. (2004) Consuming health: physicians' conflicts, patient care and developing technology, Southern California Interdisciplinary Law Journal [online], available at: http:// lawweb.usc.edu/why/students/orgs/ilj/assets/do cs/14-1\%20Myers.pdf (accessed December 29, 2010).

Power, C. \& Kohlberg, L. (1981) Moral development, religious thinking, and the question of a seventh stage, Zygon, 16, pp. 203-259.

Scambler, G. (2001). Habermas, critical theory and health. $1^{\text {st }}$.ed. New York: Routledge, pp. 15-80.

Sinclair, T. (2005) Mad, bad, or sad?: Ideology, distorted communication and child abuse prevention. Journal of Sociology, 41(3), pp. 227-246.

Sindhvananda, W. (2010) Causal paths of communicative actions and strategic actions in physicians' communication regarding passive euthanasia, Thesis, (PhD), Mahidol University.

Waitzkin, H. (1989) A critical theory of medical discourse: ideology, social control and the processing of social context in medical encounters, Journal of Health and Social Behaviour, 30, pp. 220-239. 